\title{
BMJ Open Clinical features of genetic Creutzfeldt-Jakob disease with V180I mutation in the prion protein gene
}

Temu Qina, ${ }^{1}$ Nobuo Sanjo, ${ }^{1}$ Masaki Hizume, ${ }^{1}$ Maya Higuma, ${ }^{1}$ Makoto Tomita, ${ }^{2}$ Ryuichiro Atarashi, ${ }^{3}$ Katsuya Satoh, ${ }^{3}$ Ichiro Nozaki, ${ }^{4}$ Tsuyoshi Hamaguchi, ${ }^{5}$ Yosikazu Nakamura, ${ }^{6}$ Atsushi Kobayashi, ${ }^{7}$ Tetsuyuki Kitamoto, ${ }^{7}$ Shigeo Murayama, ${ }^{8}$ Hiroyuki Murai, ${ }^{9}$ Masahito Yamada, ${ }^{5}$ Hidehiro Mizusawa ${ }^{1}$

To cite: Qina T, Sanjo N, Hizume M, et al. Clinical features of genetic Creutzfeldt-Jakob disease with V180I mutation in the prion protein gene. BMJ Open 2014;4:e004968. doi:10.1136/bmjopen-2014004968

- Prepublication history for this paper is available online To view these files please visit the journal online (http://dx.doi.org/10.1136/ bmjopen-2014-004968).

Received 30 January 2014 Revised 8 April 2014 Accepted 17 April 2014

CrossMark

For numbered affiliations see end of article.

Correspondence to

Dr Nobuo Sanjo;

n-sanjo.nuro@tmd.ac.jp

\section{ABSTRACT}

Objectives: Genetic Creutzfeldt-Jakob disease (CJD) due to $\mathrm{V} 180 \mathrm{l}$ mutation in the prion protein gene (PRNP) is of great interest because of the differences from sporadic CJD and other genetic prion diseases in terms of clinical features, as well as pathological and biochemical findings. However, few systematic observations about the clinical features in patients with this unique mutation have been published. Therefore, the goal of this study was to relate this mutation to other forms of CJD from a clinical perspective.

Design: We analysed clinical symptoms, prion protein genetics, biomarkers in cerebrospinal fluid (CSF) and MRI of patients.

Participants: 186 Japanese patients with the V180I mutation in PRNP.

Results: Our results indicate that the V180I mutation caused CJD at an older age, with a slower progression and a lower possibility of developing myoclonus, cerebellar, pyramidal signs and visual disturbance compared with classical sporadic CJD with methionine homozygosity at codon 129 of PRNP. Cognitive impairment was the major symptom. Diffuse hyperintensity of the cerebral cortex in diffusionweighted MRI might be helpful for diagnosis. Owing to the low positivity of $\mathrm{PrP}^{\mathrm{Sc}}$ in the CSF, genetic analysis was often required for a differential diagnosis from slowly progressive dementia.

Conclusions: We conclude that the V180I mutation in PRNP produces a late-developing and slow-developing, less severe form of CJD, whose lesions are uniquely distributed compared with sporadic and other genetic forms of CJD.

\section{INTRODUCTION}

Prion diseases are transmissible and lethal neurodegenerative diseases that affect humans and animals. ${ }^{1}$ In humans, prion disease can be categorised into sporadic, acquired and genetic forms. ${ }^{2}$ The genetic form of prion disease $(\mathrm{gPrD})$ that is caused by mutations in the prion protein gene

\section{Strengths and limitations of this study}

- The study used the largest V180I prion protein mutation cohort yet to be published to improve statistical power.

- The study compared the V180l variant of CJD to other genetic and sporadic variants of CJD, not just to non-CJD controls, allowing comparisons to be made across the spectrum of prion diseases.

- The study compared the V180l variant with regard to other mutations (the 129 and 219 codon polymorphisms) known to alter disease progression in other variants.

- The study was limited by focusing primarily on clinical features and retrospective data, making interpretation of the potential mechanisms differentiating disease progression in V180I and other CJD variants difficult or impossible without future studies.

(PRNP) accounts for $10.2 \%$ of cases in Europe and $16.7 \%$ in Japan. ${ }^{34}$

The epidemiological distributions of patients with $\mathrm{gPrD}$ were reported to be different between European countries and Japan. While the E200K mutation occurs most frequently in Europe, ${ }^{3}$ the V180I mutation is the most frequent mutation in Japan. ${ }^{5}$ Currently, several reports indicate that the V180I mutation in PRNP accounts for specific clinical and pathological findings. ${ }^{5-8}$ Because patients with V180I rarely have a family history of the disease, the question of whether this mutation causes prion disease persists. On the other hand, patients with V180I show several specific clinical features different from those of sporadic Creutzfeldt-Jakob disease (sCJD) or other gPrDs. ${ }^{9}$ We have previously reviewed clinical symptoms and cerebrospinal fluid (CSF) markers of several PRNP mutations, including V180I. ${ }^{5}$ Patients with V180I are readily 
distinguishable from patients with other dementia because they show specific hyperintensity in the cerebral cortex in diffusion-weighted MRI. We present some clinical features in genetic CJD (gCJD) with V180I and Alzheimer's disease in table 1.

In the current study, in order to better elucidate the clinical characteristics of the V180I mutation, we analysed the surveillance data of 186 patients with V180I, including the occurrence rate of neurological symptoms, the period of time between disease onset and the occurrence of these symptoms, biomarkers in the CSF, MRI and EEG data, and codon 129 polymorphism in PRNP. Our study indicates that myoclonus and periodic sharp wave complexes (PSWCs) in the EEG, which are included in the diagnostic criteria of CJD, occur less frequently in patients with V180I.

\section{METHODS}

Patients

The Prion Disease Surveillance Committee in Japan diagnosed gPrDs in accordance with the WHO Case Definition Criteria for epidemiological surveillance. Information on each patient was collected between April 1999 and September 2013, after the current Prion Disease Surveillance Committee of Japan began the comprehensive surveillance on prion diseases in Japan. In the current study, we analysed the surveillance data of 186 patients with definite or probable gPrD with a V180I mutation. In order to differentiate clinical features of patients with V180I from sCJD, we compared the V180I patient group with patients having sCJD with type-1 $\mathrm{PrP}^{\mathrm{Sc}}$ and methionine homozygosity at codon 129 (sCJD-MM1) of PRNP, a classical type of prion disease. In this study, 59 patients with sCJD-MM1 with definitive diagnosis were included as a control.

\section{Clinical analysis}

We collected information on age of onset, sex, family history, clinical duration of each sign or symptom (duration from onset to death, or to the point when we confirmed the condition of the patient if he or she was alive and to the point when clinical signs were observed) and

Table 1 Comparison of clinical characteristics between gPrD-V180l and Alzheimer's disease (AD)

\begin{tabular}{lll} 
& gPrD-V180I & AD \\
\hline Age at onset (years) & Late $70 \mathrm{~s}$ & Early $70 \mathrm{~s}$ \\
$\begin{array}{l}\text { Period from onset to } \\
\text { death (years) }\end{array}$ & $2-3$ & $4-8$ \\
Myoclonus & + & Late stage \\
PSWCs on EEG & +- & - \\
MRI findings & Cortical & Hippocampal \\
& hyperintensity & atrophy \\
CSF findings & Total $\tau \uparrow \uparrow \uparrow$, PrPSc $(+)$ & A $\beta 42 \downarrow$ \\
\hline CSF, cerebrospinal fluid; gPrD, genetic form of prion disease; \\
PSWCs, periodic sharp wave complexes.
\end{tabular}

the clinical signs themselves (first symptom, dementia, psychological disturbance, cerebellar disturbance, visual disturbance, pyramidal or extrapyramidal signs, myoclonus and akinetic mutism). The appearance of PSWCs in the EEG and hyperintensities in the MRI was examined as previously described ${ }^{4}$ The open reading frame and polymorphisms of codons 129 and 219 of the PRNP gene were analysed after genomic DNA was extracted from the patients' blood, as previously described. ${ }^{10}$

\section{CSF biomarkers}

CSF analysis of all patients was performed at Nagasaki University. ${ }^{11}$ We evaluated $14-3-3$ and total $\tau(\mathrm{t}-\tau)$ protein levels in the CSF by western blotting as previously described. ${ }^{5} \mathrm{PrP}^{\mathrm{Sc}}$ in the CSF was detected by real-time quaking induced conversion (RT-QUIC), as previously described. ${ }^{12}$ Briefly, CSF was incubated with recombinant human prion protein (residues 23-231 of human $\mathrm{PrP}$ with methionine at codon 129 ) at $37^{\circ} \mathrm{C}$ with intermittent shaking. Four wells were tested twice for each CSF sample and the sample was decided as positive when two or more of the four wells showed more than 1000 reactive fluorescence units (thioflavin $\mathrm{T}$ ) within $48 \mathrm{~h}$. The kinetics of fibril formation was monitored by reading the fluorescence intensity every $10 \mathrm{~min}$.

\section{Statistical analysis}

The Mann-Whitney U test was used for the statistical comparisons of age of onset, disease duration and the level of $\tau$ protein in the CSF. Fisher's exact probability test was used for the comparisons of sex, the rate of occurrence of each clinical sign, presence of PSWCs in the EEG, presence of hyperintensity in the MRI and rate of positive detection of 14-3-3 and $\mathrm{PrP}^{\mathrm{Sc}}$ proteins. For analysis of the correlation between CSF markers and each clinical parameter, analysis of variance or multiple comparison tests $\left(\chi^{2}\right.$ and Kruskal-Wallis) were used. Significance was defined as $\mathrm{p}<0.05$. Analyses were performed using GraphPad Prism 5 software (GraphPad Software, La Jolla, California, USA) and IBM SPSS Statistics (IBM, New York, New York, USA).

\section{Ethical issues}

Informed consent from the family of each patient was obtained for the current study. The study was performed in accordance with the ethical standards laid down by the 2013 Declaration of Helsinki.

\section{RESULTS}

\section{Comparison of clinical features between patients with V180I-MIM and SCJD-MM1}

Since gCJD with V180I mutation contains codon 129 methionine homozygosity (129MM) and methionine/ valine heterozygosity (129MV), we compared patients with V180I and 129MM (V180I-MM) and sCJD-MM1 or MM2 (table 2), and V180I-MV and sCJD-MV (there are no pathologically defined MV1 cases in Japan; table 3). 
Table 2 Clinical features of codon 129 homozygosity of methionine among V180I, sCJD-MM1 and sCJD-MM2

\begin{tabular}{|c|c|c|c|c|c|}
\hline & $\begin{array}{l}\text { V180I-MM } \\
n=139\end{array}$ & $\begin{array}{l}\text { sCJD-MM1 } \\
\mathrm{n}=59\end{array}$ & $\begin{array}{l}\text { p Value } \\
\text { (vs V180I-MM) }\end{array}$ & $\begin{array}{l}\text { sCJD-MM2 } \\
\mathrm{n}=8\end{array}$ & $\begin{array}{l}\text { p Value } \\
\text { (vs V180I-MM) }\end{array}$ \\
\hline Male/female & $58 / 81$ & $25 / 34$ & & $5 / 3$ & 0.53 \\
\hline Codon 219 & $135 \mathrm{EE} ; 4 \mathrm{NA}$ & $54 \mathrm{EE} ; 5 \mathrm{NA}$ & & $8 \mathrm{EE}$ & \\
\hline Age at onset (years) ${ }^{\star}$ & $\begin{array}{l}77.3 \pm 6.8(78,44-93 \\
n=139)\end{array}$ & $\begin{array}{l}68.9 \pm 9.1(70,40-89 \\
n=59)\end{array}$ & $<0.001$ & $\begin{array}{l}60.3 \pm 11.9(63,43-74 \\
n=8)\end{array}$ & $<0.001$ \\
\hline Period from onset to death (months) ${ }^{*}$ & $\begin{array}{l}23.1 \pm 15.1(19,5-70 \\
n=75)\end{array}$ & $\begin{array}{l}17.2 \pm 12.5(15,1-60 \\
n=57)\end{array}$ & 0.032 & $\begin{array}{l}22.3 \pm 12.0(20,10-50 \\
n=8)\end{array}$ & 0.98 \\
\hline Myoclonust & $46 / 130(35.4 \%)$ & $52 / 59(88.1 \%)$ & & $4 / 8(50 \%)$ & $<0.001$ \\
\hline Period from onset to myoclonus (months) ${ }^{\star}$ & $6.4 \pm 6.1(5,0-36, n=38)$ & $2.0 \pm 2.4(1,0-13, n=49)$ & $<0.001$ & $7.3 \pm 4.0(8,3-11, n=3)$ & 0.92 \\
\hline Cognitive impairment† & $138 / 138(100 \%)$ & $59 / 59(100 \%)$ & & $8 / 8(100 \%)$ & 1 \\
\hline $\begin{array}{l}\text { Period from onset to cognitive impairment } \\
\text { (months) })^{*} \ddagger\end{array}$ & $0.5 \pm 1.4(0,0-7, n=121)$ & $0.6 \pm 1.0(0,0-6, n=55)$ & 1 & $\begin{array}{l}15.6 \pm 40.3(0,0-115 \\
n=8)\end{array}$ & $<0.001$ \\
\hline Pyramidal signs $†$ & $66 / 132(50 \%)$ & $40 / 54(74.1 \%)$ & & $2 / 7(28.6 \%)$ & 0.004 \\
\hline Period from onset to pyramidal sign (months) ${ }^{*}$ & $3.9 \pm 5.8(2.5,0-36, n=58)$ & $2.9 \pm 4.4(2,0-24, n=38)$ & 0.53 & $12(n=1)$ & \\
\hline Extrapyramidal signs $\dagger$ & $71 / 133(53.4 \%)$ & $30 / 52(57.7 \%)$ & & $2 / 8(25.0 \%)$ & 0.23 \\
\hline $\begin{array}{l}\text { Period from onset to extrapyramidal signs } \\
\text { (months) }^{\star}\end{array}$ & $3.8 \pm 3.5(3,0-19, n=58)$ & $2.2 \pm 4.3(1,0-24, n=29)$ & 0.13 & $\begin{array}{l}13.0 \pm 1.4(13,12-14 \\
n=2)\end{array}$ & 0.002 \\
\hline Cerebellar dysfunction $†$ & $40 / 119(33.6 \%)$ & $32 / 45(71.1 \%)$ & & $3 / 7(42.9 \%)$ & $<0.001$ \\
\hline $\begin{array}{l}\text { Period from onset to cerebellar dysfunction } \\
\text { (months) }^{*}\end{array}$ & $2.9 \pm 2.7(3,0-9, n=33)$ & $0.7 \pm 0.9(1,0-3, n=31)$ & $<0.001$ & $\begin{array}{l}12.7 \pm 1.2(12,12-14 \\
n=3)\end{array}$ & $<0.001$ \\
\hline Visual disturbance & $10 / 109(9.2 \%)$ & $28 / 49(57.1 \%)$ & & $2 / 7(28.6 \%)$ & $<0.001$ \\
\hline Period from onset to visual disturbance (months) ${ }^{*}$ & $2.2 \pm 1.5(2,0-4, n=10)$ & $0.7 \pm 1.7(0,0-7, n=26)$ & 0.036 & $0(n=2)$ & 0.15 \\
\hline Psychiatric symptoms $†$ & $68 / 130(52.3 \%)$ & $32 / 51(62.7 \%)$ & & $5 / 7(71.4 \%)$ & 0.36 \\
\hline $\begin{array}{l}\text { Period from onset to psychiatric symptoms } \\
\text { (months) }^{*}\end{array}$ & $1.6 \pm 3.0(0,0-19, \mathrm{n}=62)$ & $0.8 \pm 0.9(1,0-3, n=29)$ & 0.32 & $5.3 \pm 7.1(3,0-15, n=4)$ & 0.024 \\
\hline Akinetic mutism† & $74 / 137(54.0 \%)$ & $44 / 57(77.2 \%)$ & & $2 / 8(25.0 \%)$ & 0.001 \\
\hline Period from onset to akinetic mutism (months) ${ }^{\star}$ & $9.8 \pm 6.6(8,1-27, n=64)$ & $3.6 \pm 4.3(2,0-23, n=42)$ & $<0.001$ & $18(n=2)$ & \\
\hline PSWCs on EEG† & $10 / 131(7.6 \%)$ & $55 / 59(93.2 \%)$ & & $2 / 7(28.6 \%)$ & $<0.001$ \\
\hline Hyperintensities on MRI & $135 / 136(99.3 \%)$ & $57 / 57(100 \%)$ & $<0.001$ & $5 / 8(62.5 \%)$ & 0.092 \\
\hline Positive rate of $14-3-3$ protein in CSF† & $46 / 53(86.8 \%)$ & $27 / 31(87.1 \%)$ & 1 & NA & \\
\hline Positive rate of $\mathrm{t}-\tau$ protein in CSF† & $48 / 53(90.6 \%)$ & $27 / 31(87.1 \%)$ & 0.72 & NA & \\
\hline Amount of $t-\tau$ protein in CSF $(p g / m L) *$ & $\begin{array}{l}2965 \pm 1712(2400 \\
146.0-9940.0, n=53)\end{array}$ & $\begin{array}{l}7950 \pm 8423(5450 \\
150.0-40120.0, n=29)\end{array}$ & $<0.001$ & NA & \\
\hline Positive rate of $\mathrm{PrP}^{\mathrm{Sc}}$ in $\mathrm{CSF} \dagger$ & $36 / 53(67.9 \%)$ & $27 / 30(90.0 \%)$ & 0.032 & NA & \\
\hline
\end{tabular}

Codon 219 is presented with total cases of that polymorphism type. EE means glutamic acid homozygous. NA means data not available.

Medians are compared using analysis of variance with Dunnett's post hoc test for age of onset, the period from disease onset to death or the appearance of each symptom and sign, the two-tailed Mann-Whitney U test for the period from onset to akinetic mutism and the CSF biomarker level. Frequencies of positive cases are compared using the two-tailed Fisher's exact test. ${ }^{*}$ Age of onset, period of time from disease onset to death or the appearance of each symptom and sign and CSF biomarker level are presented as mean \pm SD (median, range, cases).

†Frequencies of positive cases are presented as positive cases/total cases (percentage).

†These were zero-inflated.

CSF, cerebrospinal fluid; PSWCs, periodic sharp wave complexes; sCJD, sporadic Creutzfeldt-Jakob disease; $\mathrm{t}-\tau$, total $\tau$. 
Table 3 Clinical features of codon 129 heterozygosity of methionine/valine between V180I and SCJD-MV

\begin{tabular}{|c|c|c|c|}
\hline & $\begin{array}{l}\text { V180I-MV } \\
n=45\end{array}$ & $\begin{array}{l}\text { sCJD-MV } \\
\mathrm{n}=7\end{array}$ & p Value \\
\hline Type 1 or 2 & & 5 type $2 ; 2$ NA & \\
\hline Male/female & $20 / 25$ & $3 / 4$ & 1 \\
\hline Codon 219 & 44 EE; 1 EK & 7 EE & \\
\hline Age at onset (years) ${ }^{\star}$ & $76.7 \pm 7.6(78,57-92, n=43)$ & $62.0 \pm 7.0(62,51-73, n=7)$ & $<0.001$ \\
\hline Period from onset to death (months) ${ }^{\star}$ & $27.8 \pm 16.3(25,7-64, n=23)$ & $26.2 \pm 12.9(21,12-43, n=6)$ & 0.98 \\
\hline Myoclonus $†$ & $21 / 43(48.8 \%)$ & $5 / 7(71.4 \%)$ & 0.42 \\
\hline Period from onset to myoclonus (months) ${ }^{*}$ & $9.2 \pm 7.2(7,2-30, n=18)$ & $8.5 \pm 4.7(7.5,4-15, n=4)$ & 0.86 \\
\hline Cognitive impairment $\dagger$ & $43 / 44(97.7 \%)$ & $7 / 7(100 \%)$ & 1 \\
\hline Period from onset to cognitive impairment (months) ${ }^{\star} \ddagger$ & $0.6 \pm 1.4(0,0-5, n=38)$ & $3.0 \pm 4.5(0,0-10, n=5)$ & 0.26 \\
\hline Pyramidal signs $†$ & $14 / 42(33.3 \%)$ & $2 / 6(33.3 \%)$ & 1 \\
\hline Period from onset to pyramidal sign (months) ${ }^{*}$ & $5.2 \pm 4.2(5,0-14, n=11)$ & $12(n=1)$ & \\
\hline Extrapyramidal signst & $23 / 40(57.5 \%)$ & $5 / 6(83.3 \%)$ & 0.23 \\
\hline Period from onset to extrapyramidal signs (months)* & $3.8 \pm 4.5(2,0-16, n=18)$ & $5.5 \pm 6.6(4,0-15, n=4)$ & 0.58 \\
\hline Cerebellar dysfunction $\dagger$ & $12 / 38(31.6 \%)$ & $6 / 6(100 \%)$ & 0.003 \\
\hline Period from onset to cerebellar dysfunction (months)* & $3.4 \pm 4.1(3,0-12, n=8)$ & $5.8 \pm 5.4(4,0-14, n=5)$ & 0.50 \\
\hline Visual disturbance $†$ & $1 / 34(2.9 \%)$ & $1 / 5(20 \%)$ & 0.24 \\
\hline Period from onset to visual disturbance (months)* & $(n=0)$ & $(n=0)$ & \\
\hline Psychiatric symptoms $†$ & $16 / 38(42.1 \%)$ & $3 / 7(42.9 \%)$ & 1 \\
\hline Period from onset to psychiatric symptoms (months)* & $2.0 \pm 2.6(0,0-7, n=13)$ & $4.5 \pm 2.1(5,3-6, n=2)$ & 0.24 \\
\hline Akinetic mutism $\dagger$ & $30 / 44(68.2 \%)$ & $3 / 7(42.9 \%)$ & 0.23 \\
\hline Period from onset to akinetic mutism (months)* & $13.2 \pm 10.9(9,0-49, \mathrm{n}=23)$ & $12.5 \pm 5.0(13,9-16, n=2)$ & \\
\hline PSWCs on EEG† & $5 / 39(12.8 \%)$ & $2 / 6(33.3 \%)$ & 0.23 \\
\hline Hyperintensities on MRI & $44 / 44(100 \%)$ & $7 / 7(100 \%)$ & 1 \\
\hline Positive rate of $14-3-3$ protein in CSF† & $11 / 18(61.1 \%)$ & NA & \\
\hline Positive rate of $\mathrm{t}-\tau$ protein in CSF† & $12 / 18(66.7 \%)$ & NA & \\
\hline Amount of $\mathrm{t}-\tau$ protein in $\mathrm{CSF}(\mathrm{pg} / \mathrm{mL})^{*}$ & $\begin{array}{l}2025 \pm 1441(1689 \\
170.0-6430.0, n=18)\end{array}$ & NA & \\
\hline Positive rate of $\mathrm{PrP}^{\mathrm{Sc}}$ in $\mathrm{CSF} \dagger$ & $7 / 18(38.9 \%)$ & NA & \\
\hline \multicolumn{4}{|c|}{$\begin{array}{l}\text { Codon } 219 \text { is presented with total cases of that polymorphism type. EE and EK mean glutamic acid and glycine homozygous, respectively. } \\
\text { NA means data not available. } \\
\text { Medians are compared using the two-tailed Mann-Whitney U test for age of onset, the period from disease onset to death or the appearance } \\
\text { of each symptom and sign and the CSF biomarker level. Frequencies of positive cases are compared using the two-tailed Fisher's exact test. } \\
\text { *Age at onset, period of time from disease onset to death or the appearance of each symptom and sign and CSF biomarker level are } \\
\text { presented as mean } \pm S D \text { (median, range, cases). } \\
\dagger \text { Frequencies of positive cases are presented as positive cases/total cases (percentage). } \\
\ddagger \text { These were zero-inflated. } \\
\text { CSF, cerebrospinal fluid; PSWCs, periodic sharp wave complexes; sCJD, sporadic Creutzfeldt-Jakob disease; t- } \tau \text {, total } \tau \text {. }\end{array}$} \\
\hline
\end{tabular}

The average age of onset in V180I-MM and V180I-MV was about 10 years older than those of sCJD-MM1 and sCJD-MM2, and MV2, respectively. The period from disease onset to death was longer in V180I-MM than in sCJD-MM1, as previously reported, ${ }^{4}$ but was almost the same as in sCJD-MM2 (table 2). Among the 16 total autopsied patients with V180I in this cohort, few patients had additional neuropathological alterations such as Alzheimer's disease. ${ }^{6} 7$ There was no difference between definite and probable or possible cases with V180I mutation. The periods from onset to the occurrence of myoclonus, cerebellar dysfunction, visual disturbance and akinetic mutism in V180I-MM were significantly longer than those in sCJD-MM1. However, except for visual disturbance, the length of onset to the occurrence of all other signs was shorter than those in sCJD-MM2 (table 2 ). As for the clinical features of $129 \mathrm{MV}$, there was no significant difference between V180I-MV and sCJD-MV, except for age of onset (table 3 ).
The analysis of the probability of occurrence of neurological symptoms and signs similarly demonstrated reduced severity in patients with V180I-MM compared to those with sCJD-MM1. While $88.1 \%$ of patients with sCJD-MM1 developed myoclonus, only $35.4 \%$ of patients with V180I developed myoclonus. Pyramidal signs, cerebellar dysfunction, visual disturbance and akinetic mutism were also less frequent in patients with V180I-MM1 than in patients with sCJD-MM1. However, as previously reported, ${ }^{9}$ cerebellar and visual systems were not completely spared in patients with V180I.

\section{EEG and MRI findings}

PSWCs were observed in only $7.3 \%$ of patients with V180I-MM, but in over $90 \%$ of patients with sCJD-MM1 (table 2). MRI revealed hyperintensities with a similar positive rate in V180I-MM and sCJD-MM1, but was observed less frequently in patients with sCJD-MM2. The 
Table 4 Effects of the codon 129 polymorphism on the clinical features of V180I

\begin{tabular}{|c|c|c|c|}
\hline & $\begin{array}{l}\text { 129MM } \\
n=139\end{array}$ & $\begin{array}{l}\text { 129MV } \\
n=45\end{array}$ & p Value \\
\hline Male/female & $58 / 81$ & $20 / 25$ & 0.862 \\
\hline Age at onset (years) ${ }^{*}$ & $77.3 \pm 6.8(78,44-93, n=139)$ & $76.7 \pm 7.6(78,57-92, n=45)$ & 0.701 \\
\hline Period from onset to death (months) ${ }^{*}$ & $23.1 \pm 15.1(19,5-70, n=75)$ & $27.8 \pm 16.3(25,7-64, n=23)$ & 0.159 \\
\hline Myoclonust & $46 / 130(35.4 \%)$ & $21 / 43(48.8 \%)$ & 0.149 \\
\hline Period from onset to myoclonus (months) ${ }^{\star}$ & $6.4 \pm 6.1(5,0-36, n=38)$ & $9.2 \pm 7.2(7,2-30, n=18)$ & 0.154 \\
\hline Cognitive impairment $†$ & $138 / 138(100.0 \%)$ & $43 / 44(97.7 \%)$ & 0.242 \\
\hline Period from onset to cognitive impairment (months)* & $0.5 \pm 1.4(0,0-7, n=121)$ & $0.6 \pm 1.4(0,0-5, n=38)$ & 0.456 \\
\hline Pyramidal signs $\dagger$ & $66 / 132(50.0 \%)$ & $14 / 42(33.3 \%)$ & 0.075 \\
\hline Period from onset to pyramidal signs (months)* & $3.9 \pm 5.8(3,0-36, n=58)$ & $5.2 \pm 4.2(5,0-14, n=11)$ & 0.136 \\
\hline Extrapyramidal signs $†$ & $71 / 133(53.4 \%)$ & $23 / 40(57.5 \%)$ & 0.719 \\
\hline Period from onset to extrapyramidal signs (months)* & $3.8 \pm 3.5(3,0-19, n=58)$ & $3.8 \pm 4.5(2,0-16, n=18)$ & 0.460 \\
\hline Cerebellar dysfunction $\dagger$ & $40 / 119(33.6 \%)$ & $12 / 38(31.6 \%)$ & 1.000 \\
\hline Period from onset to cerebellar dysfunction (months)* & $2.9 \pm 2.7(3,0-9, n=33)$ & $3.4 \pm 4.1(3,0-12, n=8)$ & 0.973 \\
\hline Visual disturbance $†$ & $10 / 109(9.2 \%)$ & $1 / 34(2.9 \%)$ & 0.460 \\
\hline Period from onset to visual disturbance (months)* & $2.2 \pm 1.5(2,0-4, n=10)$ & $(n=0)$ & NA \\
\hline Psychiatric symptoms $\dagger$ & $68 / 130(52.3 \%)$ & $16 / 38(42.1 \%)$ & 0.357 \\
\hline Period from onset to psychiatric symptoms (months)* & $1.6 \pm 3.0(0,0-19, n=62)$ & $2.0 \pm 2.6(0,0-7, n=13)$ & 0.576 \\
\hline Akinetic mutism $\dagger$ & $74 / 137(54.0 \%)$ & $30 / 44(68.2 \%)$ & 0.116 \\
\hline Period from onset to akinetic mutism (months)* & $9.8 \pm 6.6(8,1-27, n=64)$ & $13.2 \pm 10.9(9,0-49, n=23)$ & 0.190 \\
\hline PSWCS on EEG† & $10 / 131(7.6 \%)$ & $5 / 39(12.8 \%)$ & 0.339 \\
\hline Hyperintensities on MRI† & $135 / 136(99.3 \%)$ & $44 / 44(100.0 \%)$ & 1.000 \\
\hline Positive rate of $14-3-3$ protein in CSF† & $46 / 53(86.8 \%)$ & $11 / 18(61.1 \%)$ & 0.035 \\
\hline Positive rate of $\mathrm{t}-\tau$ protein in CSF† & $48 / 53(90.6 \%)$ & $12 / 18(66.7 \%)$ & 0.014 \\
\hline Amount of $\mathrm{t}-\tau$ protein in $\mathrm{CSF}(\mathrm{pg} / \mathrm{mL})^{*}$ & $\begin{array}{l}2965 \pm 1712(2400 \\
146.0-9940.0, n=53)\end{array}$ & $\begin{array}{l}2025 \pm 1441(1689 \\
170.0-6430.0, n=18)\end{array}$ & 0.022 \\
\hline Positive rate of $\mathrm{PrP}^{\mathrm{Sc}}$ in $\mathrm{CSF} \dagger$ & $36 / 53(67.9 \%)$ & $7 / 18(38.9 \%)$ & 0.049 \\
\hline
\end{tabular}

pattern of hyperintensities in patients with V180I was uniquely distributed in the cerebral cortex.

\section{Effect of PRNP polymorphism on clinical symptoms and signs of V180I}

We also analysed the effect of the codon 129 polymorphism on the clinical symptoms of patients with V180I (table 4).

In a total of 184 patients with V180I, 139 patients $(75.5 \%)$ were $129 \mathrm{MM}$, while the remaining $45(24.5 \%)$ were $129 \mathrm{MV}$. We detected only three patients with the V180I mutation on the same allele as valine. In this case, the clinical features were no different from those with the mutation on the same allele as methionine. We also analysed the codon 219 polymorphism in 179 patients with V180I and 54 patients with sCJD-MM1, all of whom showed glutamic acid homozygosity (table 2 ). When analysing the influence of the codon 129 polymorphism on clinical symptoms and signs in patients with V180I, no symptoms or signs, in terms of the occurrence rate and the speed to develop them after disease onset, were affected by codon $129 \mathrm{MV}$.

\section{CSF biomarkers}

Positive tests of the CSF 14-3-3 protein and $t-\tau$ proteins in patients with V180I-MM were similar to those of patients with sCJD-MM1 (table 2). However, the median value of $t-\tau$ proteins in the CSF of patients with V180I-MM was significantly lower than that of patients with sCJD-MM1. In patients with V180I-MM, we found fewer positive tests for $\mathrm{PrP}^{\mathrm{Sc}}$ in the $\mathrm{CSF}$ than in patients with sCJD-MM1. Patients with V180I-MV, in particular, showed significantly fewer positive tests for 14-3-3, t- $\tau$ protein and $\mathrm{PrP}^{\mathrm{Sc}}$ in the $\mathrm{CSF}$, as well as in the amount of CSF $t-\tau(p=0.034,0.023,0.001$ and $<0.001$, respectively; multiple comparison using Fisher's exact and Kruskal-Wallis tests).

\section{Effect of age}

In order to exclude whether any variables were age dependent, we compared some laboratory and CSF findings in patients with V180I and with sCJD older than 75 years (table 5 ). We found that positive rates of $\mathrm{PrP}^{\mathrm{Sc}}$ were comparable, although whether the greater percentage of older patients with $\mathrm{PrP}^{\mathrm{Sc}}$ is age dependent or due to the small sample size is currently unclear. 
Table 5 Laboratory and CSF findings of gPrD-V180I compared to sCJD older than 75 years

\begin{tabular}{|c|c|c|c|}
\hline & $\begin{array}{l}V 180 I \\
n=186\end{array}$ & $\begin{array}{l}\text { sCJD (>75 years) } \\
n=11\end{array}$ & p Value \\
\hline Male/female & $78 / 108$ & $25 / 34$ & 1.00 \\
\hline Age at onset (years) ${ }^{*}$ & $77.2 \pm 6.9(78,44-93)$ & $80.9 \pm 4.2(80,76-89)$ & 0.056 \\
\hline PSWCs on EEG† & $16 / 172(9.3 \%)$ & $10 / 11(90.9 \%)$ & $<0.001$ \\
\hline Positive rate of $14-3-3$ protein in CSF† & $57 / 71(80.2 \%)$ & $7 / 8(87.5 \%)$ & 1.00 \\
\hline Positive rate of $t-\tau$ protein in CSF $\dagger$ & $61 / 71(85.9 \%)$ & $6 / 8(75.0 \%)$ & 0.60 \\
\hline Amount of $\mathrm{t}-\tau$ protein in $\mathrm{CSF}(\mathrm{pg} / \mathrm{mL})^{*}$ & $\begin{array}{l}2727 \pm 1688(2400 \\
146.0-9940.0, n=71)\end{array}$ & $\begin{array}{l}6569.8 \pm 4270.3(8995.0 \\
150.0-10290.0, n=8)\end{array}$ & 0.035 \\
\hline Positive rate of $\mathrm{PrPSc}^{\mathrm{Sc}}$ in CSF† & $44 / 71(62.0 \%)$ & $7 / 8(87.5 \%)$ & 0.246 \\
\hline \multicolumn{4}{|c|}{$\begin{array}{l}\text { Medians are compared using the two-tailed Mann-Whitney U test for age at onset, the period from disease onset to death or the appearance } \\
\text { of each symptom and sign and the CSF biomarker level. Frequencies of positive cases are compared using the two-tailed Fisher's exact test. } \\
\text { "Age at onset and the appearance of CSF biomarker level are presented with mean } \pm S D \text { (median, range, case number). } \\
\text { †Frequencies of positive cases are presented with positive case number/total case number (percentage). } \\
\text { CSF, cerebrospinal fluid; gPrD, genetic form of prion disease; PSWCs, periodic sharp wave complexes; sCJD, sporadic Creutzfeldt-Jakob } \\
\text { disease; t- } \tau \text {, total } \tau \text {. }\end{array}$} \\
\hline
\end{tabular}

\section{DISCUSSION}

With a very rare incidence in Europe,$^{3}$ the V180I mutation was geoepidemiologically discovered mainly in Japan, and has turned out to be the most common cause of $g \operatorname{PrD}$ in Japan. ${ }^{5}$ The reason for this geographical distribution difference is currently unclear, but racial and/or environmental factors are most likely involved.

Of the patients with V180I $\mathrm{gPrD}, 78$ cases were of male patients and 108 cases were female, indicating a possible gender influence on the susceptibility of this mutation in the disease. Similar to other mutations in PRNP, women appear more susceptible. ${ }^{3}$ Patients with sCJD-MM1 were characterised by fast, severe progression of the disease, and neurological malfunctions resulting from extensive brain lesions appeared in a period of less than 3 months (table 2). However, V180I progressed relatively slowly. Myoclonus, cerebellar signs and visual dysfunctions occurred less frequently and with greater latency in patients with V180I (table 2). PSWCs in the EEG, a frequent finding in patients with sCJD-MM1, were rarely detected in patients with V180I (table 2). While a triad of dementia, myoclonus and PSWCs in the EEG is typical of sCJD, patients with V180I mainly presented with cognitive impairment and a very low rate of myoclonus in the early stages, along with rarely detectable PSWCs. Instead of possible CJD, these cases tended to be misdiagnosed as dementia due to Alzheimer's disease. MRI could facilitate the diagnosis of V180I when a specific pattern of ribbon hyperintensity lesions is detected. ${ }^{8}{ }^{13}$ However, it may still be difficult to distinguish patients with V180I from patients with sCJD-MM1 because hyperintensity was similarly detected in patients with sCJD-MM1, necessitating direct testing of the PRNP gene.

Previous reports suggested that there were no visual and cerebellar clinical symptoms in V180I, and neuroimaging of the medial occipital lobes posterior to the parieto-occipital sulcus and the cerebellum revealed that they were not involved until the terminal stage. ${ }^{9}$ These data posit V180I as a comparative analogue of $\mathrm{sCJD}^{14}$ or a cortical form of sCJD with type-2 $\mathrm{PrP}^{\mathrm{Sc}}$ and methionine homozygosity at codon $129 .{ }^{15}$ In our current study of 186 patients with V180I, we found that $34 \%$ demonstrated clinical cerebellar dysfunction, and $8.3 \%$ presented with visual disturbances (tables 2 and 3). Although no detailed description of the exact manifestations of cerebellar and visual symptoms was recorded, and a subjective bias in identifying the true origins of these symptoms should be taken into consideration, our finding indicates that in order to confirm whether the cerebellum is actually spared in patients with V180I, it is critical to analyse the pathological and immunohistochemical features including $\mathrm{PrP}^{\mathrm{Sc}}$ deposition and spongiform changes in a topological manner.

The penetrance of V180I was very low. Only 11 out of 186 patients $(5.9 \%)$ had a family history of dementia, while family member involvement in the case of other gPrD mutations, such as E200K, P102L and P105L, was frequently noted. ${ }^{35}$ Within the 11 patients with V180I in the current study who had a recorded family history, 3 patients had one family member each diagnosed with CJD. The remaining eight cases had family members of one generation above, or the same generation, who had dementia due to an unknown cause. The low penetrance of V180I, specific clinical features and MRI findings was intriguing, and leads us to speculate whether the V180I mutation is causative for the disease or is actually a disease-associated factor accompanying other protective or toxic factors. The V180I mutation is reported to have significantly higher proportions of overall prion disease $(\mathrm{n}=881$, both $\mathrm{p}<0.001),{ }^{4}$ compared with the genotypes of PRNP in the general Japanese population $(\mathrm{n}=466$; isoleucine allele at codon 180 was not detected). ${ }^{16}$ These findings indicate that the V180I mutation is not simply a polymorphism, but is indeed disease related.

Different $\operatorname{PrP}^{\mathrm{Sc}}$ glycotypes might lead to differential distributions of $\operatorname{PrP}^{\mathrm{Sc}}$ throughout the brain, ${ }^{17}{ }^{18}$ and may account for the disparate affects on brain regions 
underlying cerebral cortical symptoms as opposed to cerebellar symptoms, for instance. In this cohort, western blotting of brain homogenates from patients with V180I indicated only weak bands of the monoglycosylated and unglycosylated fragments. ${ }^{5}$ In the future, studies should examine the role of factors that influence lesion topology on the disease's clinical expression and progression. We hypothesise that the different pattern of clinical and pathological features with V180I may represent different, but still topologically defined, neuronal loss when compared with sCJD-MM1. Elucidating this mechanism would require systematic pathological, immunochemical and biochemical studies of $\operatorname{PrP}^{\mathrm{Sc}}$.

The codon 129 polymorphism in PRNP plays an important role in determining the disease phenotype and the type of $\operatorname{PrP}^{\mathrm{Sc}}$ present in sCJD. ${ }^{14} 1920$ It was also reported that the codon 129 polymorphism affects the phenotype in gPrD. ${ }^{21-23}$ In our study, while $75.5 \%$ had methionine in the normal allele (MM homozygous), $24.5 \%$ had valine in the normal allele (MV heterozygous). We observed that when the codon 129 polymorphism occurred in the allele opposite to the V180I mutation, its influence on the clinical symptoms and signs were similar to the wild type MV polymorphism (table 4). However, the MV polymorphism in codon 129 significantly lowered the positive test rate and amount of CSF biomarkers such as the 14-3-3 protein, $\tau$ protein and $\mathrm{PrP}^{\mathrm{Sc}}$ positivity, suggesting that the codon 129 polymorphism may contribute to the severity and/or speed of neurological degeneration. Moreover, there might be other unknown disease modifying factors that contribute to the clinical features and course of genetic prion disease. In addition, the codon 129 and 219 polymorphisms have been reported to be risk and protective factors, respectively, for sCJD. ${ }^{24-27}$ In our study, similar to the study of patients with sCJD-MM1, all patients with V180I tested for the codon 219 polymorphism were glutamic acid homozygous (table 2). This result further suggests that codon 219 heterozygosity would be a protective factor in resisting prion disease onset. Interestingly, the frequency of codon 129 in MV heterozygous patients with the V180I mutation is greater than that in the general Japanese population, creating a discrepancy in the hypothesis that codon 129 homozygosity increases the susceptibility to prion disease.

Although there are several reports describing V180I in terms of its clinical features, imaging characteristics, pathology, immunohistochemistry and biochemistry, most were either case reports or analyses of a small number of cases. ${ }^{6-8} 28-31$ To the best of our knowledge, the current study is the first large cohort clinical study of V180I. From this study, we conclude the clinical features of V180I to be as follows: (1) a late age of onset and slow progression; (2) a relatively low occurrence rate, and slow development of symptoms such as myoclonus, cerebellar abnormalities and visual disturbances; (3) a low detectable rate of PSWCs in EEGs, and a high detectable rate of hyperintensity in diffusion-weighted or fluid-attenuated inversion recovery imaging; (4) lower t- $\tau$ protein levels in the CSF versus SCJD-MM1 and (5) an extremely low likelihood of a family history of V180I.

Author affiliations

${ }^{1}$ Department of Neurology and Neurological Science, Tokyo Medical and Dental University Graduate School of Medical and Dental Sciences, Tokyo, Japan

${ }^{2}$ Faculty of Medicine, Clinical Research Center, Tokyo Medical and Dental University, Tokyo, Japan

${ }^{3}$ Department of Molecular Microbiology and Immunology, Nagasaki University Graduate School of Biomedical Sciences, Nagasaki, Japan

${ }^{4}$ Department of Neurology, National Hospital Organization lou Hospital,

Kanazawa, Japan

${ }^{5}$ Department of Neurology and Neurobiology of Aging, Kanazawa University Graduate School of Medical Science, Kanazawa, Japan

${ }^{6}$ Department of Public Health, Jichi Medical University, Tochigi, Japan ${ }^{7}$ Division of CJD Science and Technology, Department of Prion Protein Research, Tohoku University Graduate School of Medicine, Miyagi, Japan ${ }^{8}$ Department of Neurology and Neuropathology, Tokyo Metropolitan Geriatric Hospital and Institute of Gerontology, Tokyo, Japan

${ }^{9}$ Department of Neurology, Neurological Institute, Kyushu University Graduate School of Medicine, Fukuoka, Japan

Acknowledgements The authors are grateful to all the members of the Prion Disease Surveillance Committee, Japan, for collecting data and offering advice. They also thank the patients with CJD and their families for providing clinical information about the patients. Our manuscript has been edited by professional native English-speaking editors (http://www.editage.jp).

Contributors TQ drafted the manuscript and analysed the data. NS and M Hizume revised the manuscript, designed the study and analysed the data. NS and MT performed the statistical analysis and obtained funding. RA and KS analysed the CSF samples. M Higuma, IN, TH, SM and AK coordinated the study. TK analysed the prion protein gene and supervised the study. YN collected patient data. MY and HM supervised this study.

Funding The contributions of NS, YN, TK, MY and HM to this study were supported in part by a Health and Labour Sciences Research Grant for Research on Measures for Intractable Diseases (Prion Disease and Slow Virus Infections, the Research Committee on Surveillance and Infection Control of Prion Disease) from the Ministry of Health, Labour and Welfare of the Japanese government.

\section{Competing interests None.}

Patient consent Obtained.

Ethics approval Institutional Ethics Committee of Tokyo Medical and Dental University.

Provenance and peer review Not commissioned; externally peer reviewed.

Data sharing statement No additional data are available.

Open Access This is an Open Access article distributed in accordance with the Creative Commons Attribution Non Commercial (CC BY-NC 3.0) license, which permits others to distribute, remix, adapt, build upon this work noncommercially, and license their derivative works on different terms, provided the original work is properly cited and the use is non-commercial. See: http:// creativecommons.org/licenses/by-nc/3.0/

\section{REFERENCES}

1. Collinge J. Prion diseases of humans and animals: their causes and molecular basis. Annu Rev Neurosci 2001;24:519-50.

2. Ironside JW, Ritchie DL, Head MW. Phenotypic variability in human prion diseases. Neuropathol Appl Neurobiol 2005;31:565-79.

3. Kovacs GG, Puopolo M, Ladogana A, et al. Genetic prion disease: the EUROCJD experience. Hum Genet 2005;118:166-74.

4. Nozaki I, Hamaguchi T, Sanjo N, et al. Prospective 10-year surveillance of human prion diseases in Japan. Brain 2010;133:3043-57. 
5. Higuma M, Sanjo N, Satoh K, et al. Relationships between clinicopathological features and cerebrospinal fluid biomarkers in Japanese patients with genetic prion diseases. PLOS ONE 2013;8: e60003.

6. Iwasaki $\mathrm{Y}$, Mori $\mathrm{K}$, Ito M, et al. An autopsied case of V180I Creutzfeldt-Jakob disease presenting with panencephalopathic-type pathology and a characteristic prion protein type. Neuropathology 2011;31:540-8.

7. Yoshida H, Terada S, Ishizu $\mathrm{H}$, et al. An autopsy case of Creutzfeldt-Jakob disease with a V180I mutation of the PrP gene and Alzheimer-type pathology. Neuropathology 2010;30:159-64

8. Kono S, Manabe Y, Fujii D, et al. Serial diffusion-weighted MRI and SPECT findings in a Creutzfeldt-Jakob disease patient with V180I mutation. J Neurol Sci 2011;301:100-3.

9. Jin K, Shiga Y, Shibuya S, et al. Clinical features of Creutzfeldt-Jakob disease with V180l mutation. Neurology 2004;62:502-5

10. Kitamoto T, Ohta M, Doh-ura K, et al. Novel missense variants of prion protein in Creutzfeldt-Jakob disease or Gerstmann-Straussler syndrome. Biochem Biophys Res Commun 1993;191:709-14.

11. Satoh K, Tobiume M, Matsui $Y$, et al. Establishment of a standard 14-3-3 protein assay of cerebrospinal fluid as a diagnostic tool for Creutzfeldt-Jakob disease. Lab Invest 2010;90:1637-44.

12. Atarashi R, Satoh K, Sano K, et al. Ultrasensitive human prion detection in cerebrospinal fluid by real-time quaking-induced conversion. Nat Med 2011;17:175-8.

13. Terasawa $Y$, Fujita K, Izumi $Y$, et al. Early detection of familial Creutzfeldt-Jakob disease on diffusion-weighted imaging before symptom onset. J Neurol Sci 2012;319:130-2.

14. Gambetti P, Kong Q, Zou W, et al. Sporadic and familial CJD: classification and characterisation. Br Med Bull 2003;66:213-39.

15. Capellari S, Strammiello R, Saverioni D, et al. Genetic Creutzfeldt-Jakob disease and fatal familial insomnia: insights into phenotypic variability and disease pathogenesis. Acta Neuropathol 2011;121:21-37.

16. Ohkubo T, Sakasegawa Y, Asada T, et al. Absence of association between codon 129/219 polymorphisms of the prion protein gene and Alzheimer's disease in Japan. Ann Neurol 2003;54:553-4.

17. Chasseigneaux S, Haik S, Laffont-Proust I, et al. V180I mutation of the prion protein gene associated with atypical PrPSc glycosylation. Neurosci Lett 2006;408:165-9.
18. Xiao X, Yuan J, Haik S, et al. Glycoform-selective prion formation in sporadic and familial forms of prion disease. PLOS ONE 2013;8: e58786.

19. Parchi P, Castellani R, Capellari S, et al. Molecular basis of phenotypic variability in sporadic Creutzfeldt-Jakob disease. Ann Neurol 1996;39:767-78.

20. Parchi P, Strammiello R, Giese A, et al. Phenotypic variability of sporadic human prion disease and its molecular basis: past, present, and future. Acta Neuropathol 2011;121:91-112.

21. Goldfarb LG, Petersen RB, Tabaton M, et al. Fatal familial insomnia and familial Creutzfeldt-Jakob disease: disease phenotype determined by a DNA polymorphism. Science 1992;258:806-8.

22. Petersen RB, Parchi P, Richardson SL, et al. Effect of the D178N mutation and the codon 129 polymorphism on the metabolism of the prion protein. J Biol Chem 1996;271:12661-8.

23. Schelzke G, Kretzschmar HA, Zerr I. Clinical aspects of common genetic Creutzfeldt-Jakob disease. Eur J Epidemiol 2012;27:147-9.

24. Palmer MS, Dryden AJ, Hughes JT, et al. Homozygous prion protein genotype predisposes to sporadic Creutzfeldt-Jakob disease. Nature 1991;352:340-2.

25. Petraroli R, Pocchiari M. Codon 219 polymorphism of PRNP in healthy Caucasians and Creutzfeldt-Jakob disease patients. $A m \mathrm{~J}$ Hum Genet 1996;58:888-9.

26. Shibuya S, Higuchi J, Shin RW, et al. Codon 219 Lys allele of PRNP is not found in sporadic Creutzfeldt-Jakob disease. Ann Neurol 1998;43:826-8.

27. Jeong BH, Lee KH, Kim NH, et al. Association of sporadic Creutzfeldt-Jakob disease with homozygous genotypes at PRNP codons 129 and 219 in the Korean population. Neurogenetics 2005;6:229-32.

28. Yang TI, Jung DS, Ahn BY, et al. Familial Creutzfeldt-Jakob disease with V180I mutation. J Korean Med Sci 2010;25:1097-100.

29. Iwasaki Y. Three cases of Creutzfeldt-Jakob disease with prion protein gene codon 180 mutation presenting with pathological laughing and crying. J Neurol Sci 2012;319:47-50.

30. Suzuki K, Matsumura N, Suzuki T, et al. Creutzfeldt-Jakob disease with V180l mutation and senile plaque. Geriatr Gerontol Int 2009;9:210-12.

31. Mutsukura K, Satoh K, Shirabe S, et al. Familial Creutzfeldt-Jakob disease with a V180I mutation: comparative analysis with pathological findings and diffusion-weighted images. Dement Geriatr Cogn Disord 2009;28:550-7. 